exclusively devoted to problems. At the present time particular methods are prohibited in answering the questions set in certain papers; such general restrictions of methods are no longer to be maintained. A special regulation provides that at least half the questions set throughout the examination shall be of an elementary character.

The Board also proposes to abandon the custom of publishing the list of successful candidates in order of merit, and to follow the method at present adopted in the Classical Tripos. There will be three classes (Wranglers, Senior and Junior Optimes), and each class will consist of three divisions, the names in each division being arranged in alphabetical order.

The proposed changes in Part I. have involved some corresponding changes in Part II. The class-list is to consist of three divisions only, the names in each division being arranged alphabetically; and it is to be possible for a candidate to obtain a place in the first division in two ways. He may do so (as at present) by showing special proficiency in one section of the schedule of subjects, together with general proficiency in one or more other sections ; or by showing general proficiency over a wider range of subjects.

The Board hopes that these changes will induce more men to take Part I. in their second year; it is at present possible to do so under a regulation which came into force in I 893, but very few have actually availed themselves of the rule (probably not I per cent. of the whole number of candidates since 1892). This is partly due to the fact that 90 per cent. of the candidates cannot cover the whole range of reading in two years, and partly to the natural desire of the more able men to appear in as high a place as possible in the list. By taking the Tripos in their second year, men who intend to study subjects such as physics or engineering will be able to gain a preliminary knowledge of mathematics, with indications as to how to extend their knowledge in any special branch which they may need in their future course. The second year Tripos will be of advantage also to the better mathematical men, who now spend half their third year in revision and in acquiring facility of solving artificial problems. Under the proposed regulations these men will have two years after Part I. (instead of one) in which to become acquainted with the ideas and methods of modern mathematics. This will be of special advantage to men who intend to devote themselves to mathematical research.

It is thought that the abolition of order of merit will assist the aims of the Board by making it possible for the papers to be easier, and by helping to remove artificial problems ; and also by inducing a greater number of men to take the Tripos in the second year of residence. It is further felt by many that the proposed Part I. is not of sufficient extent to even profess to classify the candidates in an exact final order of merit.

On November 23 the proposals of the Board were discussed by the Senate. As might be anticipated, the scheme was criticised at some length, and particularly the proposal to abolish the order of merit. The Board will now revise its suggestions in the light of the criticisms of the Senate, and the Senate will have to vote on the final recommendations of the Board.

It seems that the present Tripos must be modified in some way, as the number of candidates has been steadily falling off in recent years. Though once the largest Tripos in the University, the Mathematical Tripos is now smaller than both the Natural Science and the Classical Tripos. Taking an average of the candidates for the four years $1869-72$, we find that, of the resident undergraduates, one in eighteen passed the Mathematical Tripos; while for the five years $1895-99$, the average falls to one in thirty-five (of course, this relates to Part I. only).

No. I 570 , voL. 6 I]

\section{THE RESISTANCE OF THE AIR.}

THE mportance of determinations of the resistance of the air to moving bodies, in connection with the problem of aërial navigation and numerous other practical applications, has led the Société d'Encouragement pour l'Industrie Nationale to offer a prize for investigations of an essentially experimental nature dealing with the reactions on a surface moving through the air under varying conditions as to form and velocity. One series of experiments with this object has been undertaken by $M$. l'Abbé Le Dantec, and a second set by M. Canovetti. The following account of these researches is based on the papers communicated by their authors to the Bulletin of the Society, and the report on them by M. Barbet.

The method adopted by M. l'Abbé Le Dantec is very simple, and had been used in some previous experiments by him in 1893. It is based on the property that the motion of a falling body is at first accelerated, but the resistance of the air, increasing as the velocity increases, soon balances the weight of the body, and the body thus soon acquires its terminal velocity, and then moves uniformly. The resistance of the air at this velocity is exactly equal to the weight of the falling body.

In the present experiments the surface whose resistance is to be observed slides down a vertical wire, which acts as a guide without introducing perceptible friction. Its weight and area can be easily and accurately measured and Le Dantec has now devised an electric recording apparatus, which enables the time of fall to be estimated with equal precision. A band of paper is unrolled by clockwork action, and on this band an electric arrangement records the vibrations of a seconds pendulum. Furthermore, when the falling surface is released, a current is started whereby a toothed wheel is brought into contact with the paper band, and traces on it a dotted line. The surface at the end of its descent comes in contact with a buffer, the current is broken, and the cessation of the dotted line indicates the exact instant at which the surface reached the buffer. The operator can vary the height in such a way that the descent occupies one, two, three or more seconds, and by subtraction the distances traversed in each successive second are obtained.

The experiments were conducted in the chapel of the Conservatoire des Arts et Métiers, the nave of which is of considerable height, and their accuracy is verified by the perfect agreement of the results. Thus several experiments conducted for the purpose of determining the height through which a surface fell in a certain number of seconds agreed to within a centimetre. The chief conclusions are as follows :-

(I) Even feeble air currents such as are produced by persons moving about in the neighbourhood of the apparatus suffice to considerably modify the results, and it is important therefore that the experiments should be conducted in a closed building, which must, however, be sufficiently large for the walls not to materially affect the stream-lines of the air flowing past the moving surface.

(2) A square surface I metre square, moving with a velocity of I metre per second, experiences a resistance of $8 \mathrm{I}$ grammes.

(3) Experiments conducted with three different surfaces, each of I square metre in area, but of different forms, viz. circular, square, and of the form of an equilateral triangle, respectively, show that the resistance depends on the form of the surface, and the results accord with the hypothesis that the resistance of a surface of given area is proportional to the length of its contour. This property appears to be new.

(4) For velocities varying within certain limits, the law of proportionality of the resistance to the square of the velocity was verified.

The resistance of the air to a moving surface can also 
be measured by attaching the surface to a small truck which is allowed to descend an inclined plane under gravity. If there were no resistance to motion the square of the velocity at any point would be equal to twice the product of the vertical height fallen into the acceleration of gravity, but since friction and atmospheric resistance retard the motion, and the latter resistance increases with the velocity, the truck soon acquires its terminal velocity, and in the uniform motion which follows, the total resistance is equal to the weight of the moving body resolved down the plane. By experimenting with the truck alone, the resistance experienced by it can be obtained separately, and by subtraction the portion of the resistance due to the surface under observation is found.

This method forms the basis of M. Canovetti's experiments. Instead, however, of an inclined plane, a copper wire was employed, three millimetres in diameter and 370 metres in length, of which one end was fixed on the side of a hill, and the other on the level ground at its base. This arrangement is similar to that used in many countries where bundles of wood are sent down from the hills by means of a wire. Owing to the wire hanging in a catenary, the lower part of the wire was much less steeply inclined than the upper, the wire even sloping upwards near its lower extremity. For this reason Canovetti did not take into account the last ninety metres of the path.

The mode of suspending the various surfaces by a trolley is shown by the accompanying figures. The wheels of the trolley were provided with ball bearings. In order to determine what part of the resistance was due to the trolley itself, the latter unloaded was allowed to descend a wire at an inclination considerably smaller than that employed when it carried one of the surfaces, the smaller resistance of the unloaded trolley rendering a reduction of the gradient necessary in order that the resistance might be calculated under similar conditions as to velocity. The experiments indicated that the resistance of the trolley alone was proportional to the velocity.

In determining the velocity, Canovetti contented himself with reading on a chronometer the instant of starting the trolley and the instant at which it passed a mast placed 90 metres in front of the stopping point. By dividing the 280 metres traversed by the time occupied between the two readings, the average velocity of descent was obtained, and this average velocity formed the basis of Canovetti's conclusions.

The most interesting of these results are those referring to the relative resistances of circular and rectangular planes, and the effects of attaching a cone or hemisphere to a circular disc forming a bow or stern. Canovetti finds that the resistance of the air on an area of one square metre moving with a velocity of I metre per second is 90 grammes for a rectangle and 80 grammes for a circle.

A right cone, whose altitude is $\mathrm{I}^{\circ} 5$ times the diameter of its base, attached to the rear face of the circle reduces the resistance to 60 grammes.

A hemisphere placed in front of the circle as a prow (Fig. I) reduces the resistance to 22.5 grammes.

Finally, in a double cone, formed by placing a cone of altitude double the diameter of the base in front of the circle, and a cone of altitude equal to the diameter of the base behind (Fig. 2), the resistance is reduced to $I_{5}$ grammes, or less than a fifth of the original resistance.

Canovetti made a series of further experiments on solids resembling in form the Chalais balloon by suspending a cone and hemisphere, joined by their bases in a net (Fig. 3). In one of these observations the resistance was equal to 80 grammes. This high resistance was due largely to the net, but also in part to the instability of motion, which caused the whole model to undulate. In

$$
\text { NO. I57O, VOL.6 I] }
$$

proof of this latter influence experiments were separately made on models rigidly attached to and freely suspended from the trolley. By taking a model formed of a cone and hemisphere, and attaching it to the trolley by rigid supports fixed one near the common base and another near

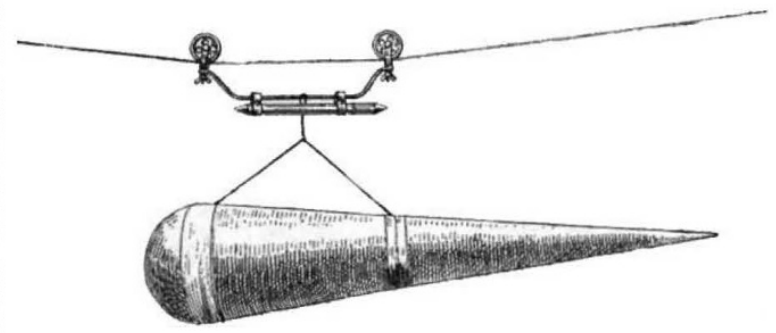

FIG. $x$.

the vertex of the cone, a coefficient of resistance equal to one-seventh of that of the corresponding circular disc was obtained.

To sum up, then, Le Dantec's experiments appear to have been conducted with every precaution to secure

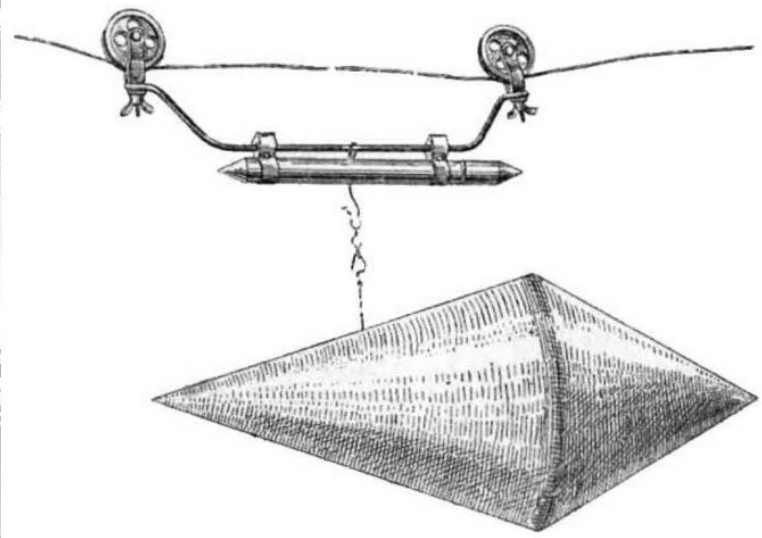

FIG. 2.

accuracy. The coefficient of resistance which he calculates from determinations made in a room from which draughts are carefully excluded must be regarded to some extent as the limiting value of a physical constant ob-

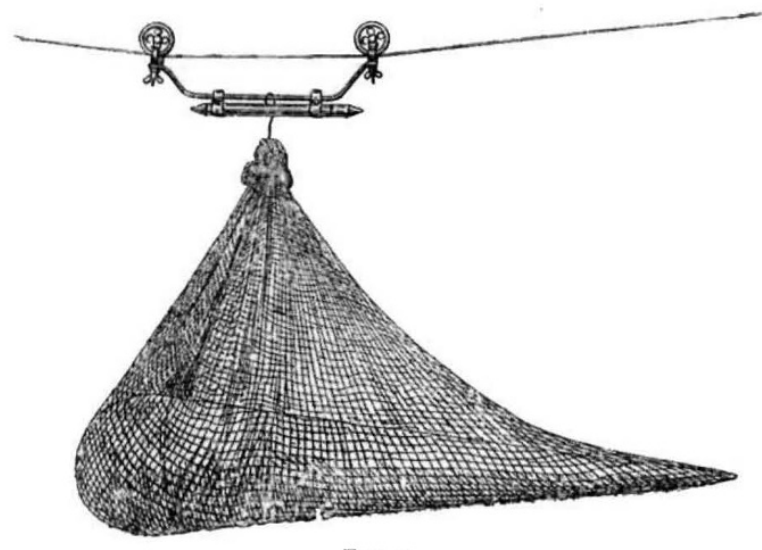

FIG. 3.

tained under conditions which are difficult to realise in practice. We may compare such determinations, e.g. with the determination of the weight of a cubic centimetre of absolutely pure water, since in all probability a large 
volume of air free from all currents and a cubic centimetre of water free from all impurities, are both of them well-nigh equally difficult of realisation. The exact determination of such constants is nevertheless of the greatest scientific interest, and even the difference between their values and those obtained under more normal conditions affords a measure of the allowance that must be made for the discrepancies which exist between theory and practice.

Canovetti's experiments, on the other hand, are essentially of the rough and ready order in several respects. The wire hanging as it does in a catenary, the differences of inclination at different parts of the course render the motion far from uniform over the 280 metres, and the estimated velocities can only be regarded as average velocities in a motion with variable velocity, the details of which have not been fully investigated. A further source of error is due to the sagging of the wire at the point where the trolley rests on it, and the consequent absorption of energy in producing vibrations. It is thus not surprising to find that Canovetti obtains 90 grammes for the resistance of a rectangle where Le Dantec finds $8 \mathrm{I}$ grammes; one might not unreasonably have expected a greater discrepancy. Although Canovetti avoided windy days, yet his experiments were conducted in the open air under conditions which might be regarded as normal in ordinary calm weather, and so far as the results bear on the question of the relative efficacies of different forms of balloons and other bodies in overcoming air resistance, they may be regarded as furnishing data of considerable practical value.

G. H. BRYAN.

\section{DR. HENRY HICKS, F.R.S.}

$\mathrm{B}^{\mathrm{RITISH}}$ geology suffers a severe loss in the death of Dr. Henry Hicks, a loss which will long be felt on personal as well as scientific grounds. His chief work was in South Wales, among the older Palæozoic formations, whose life-history was previously but little known. He pushed his inquiries into the very oldest pre-Cambrian rocks, both in Wales and Scotland; and then turning from these most ancient records he gave attention to those immediately preceding the present order of things, and pursued with equal ardour the evidences of glaciation in South Wales and Middlesex, the records of old bone-caves, and the remains of mammoth in the Thames Valley. No man had a keener eye for fossils. To him rocks which had for long been deemed unfossiliferous yielded up some evidences of life.

Now and again his enthusiasm led him to draw conclusions and express opinions that were too slenderly supported by evidence, and consequently he was brought perhaps more than any other man of his time into active conflict on the battle-field of geology. No one, however, seemed to enjoy more heartily the animated debates which his own papers so often provoked than Dr. Hicks.

Henry Hicks was born at St. David's, in Pembrokeshire, in 1837 , and was educated at the Collegiate and Chapter School in that city. Coming to London to study for the medical profession, he entered Guy's Hospital, and was admitted a Member of the Royal College of Surgeons and a Licentrate of the Society of Apothecaries in I862. Returning then to his native place he commenced a practice which he continued until $187 \mathrm{I}$, when he removed to Hendon. He now devoted special attention to mental diseases, took the M.D. degree at St. Andrews in 1878 , and continued his active and useful medical work until the close of his life.

It was in 1863 , while resident at St. David's, that Dr. Hicks' attention was first attracted to geology, and the inspiration came through the late J. W. Salter, then palæontologist to the Geological Survey. In the previous year Salter had himself discovered, for the first time in
Britain, remains of the large Trilobite Paradoxides, which was then stated to occur in the "Lower Lingula Flags," of St. David's. Dr. Hicks' interest was aroused ; he diligently commenced to search for fossils among the old rocks around him, and as he himself has told, the enthusiasm with which every new find was welcomed by Salter, "to whom they were first sent, was in itself a sufficient stimulus for any exertions required." A grant in aid was received from the British Association in 1863 , and in the following year Salter was enabled to report at the Bath meeting that the energetic work of Dr. Hicks "has already brought to light more than thirty species of fossils, most of them Trilobites"; and as he elsewhere remarked, these discoveries "made a large addition to the Primordial fauna."

With the help and encouragement thus given by Salter Dr. Hicks pursued his work with unflagging devotion. His first communication to the Geological Society was made in 1865, and dealt with the genus Anopolenus; and from that date onwards for some years he contributed a series of most important papers on the stratigraphy and palæontology of the Cambrian and Lower Silurian rocks of South Wales, two or three of the earlier papers in conjunction with Salter or Robert Harkness. These researches led to the establishment of the Menevian group in 1865 by Salter and Hicks for part of the Middle Cambrian division which is characterised by Paradoxides Davidis \&c.

In 1876 he communicated a more particular account of the pre-Cambrian rocks of Pembrokeshire, and here he came perhaps more into conflict than on any previous occasion. The granitoid rock which he named Dimetian and claimed as pre-Cambrian was regarded by Sir A. Ramsay as metamorphosed Cambrian, and afterwards by $\operatorname{Sir}$ A. Geikie as a granite mass intruded into the Cambrian rocks. The Pebidian volcanic series, also regarded as pre-Cambrian by Dr. Hicks, was grouped with the Cambrian by Sir A. Geikie. The evidence for a third and intermediate series named Arvonian by Dr. Hicks was subsequently admitted by him to be inconclusive. In his views concerning the antiquity of the Dimetian, Dr. Hicks was strongly supported by Prof. Bonney, Prof. Hughes and Mr. Thomas Davies. With regard to the Pebidian, it is now recognised that the beds are of the type of the Uriconian of Shropshire, generally classed as pre-Cambrian.

Between 1878 and I883, Dr. Hicks published a series of papers on the metamorphic and overlying rocks of parts of Ross-shire and Inverness-shire, with petrological notes by Prof. Bonney and Mr. T. Davies.

Since he went to reside at Hendon, Dr. Hicks gave much attention to the local geology, and recorded many facts of interest. In course of time the subject of bonecaves greatly occupied him, and Cae Gwyn Cave in particular was explored in company with Mr. E. B. Luxmoore and others. It was then shown that this Denbighshire cavern was occupied by an early Pleistocene fauna and by man before the deposition of any of the local glacial deposits.

In 1890 Dr. Hicks bent his steps into North Devon, and was much struck with the evidences of folding, faulting and crushing near Ilfracombe. He then for the first time found a Lingula in the Morte Slates, and expressed the opinion that these rocks were older than the Devonian. Working zealously in Devonshire, and revisiting South Pembrokeshire for the sake of comparisons, he elaborated his views in 1896 and 1897 . He had now succeeded in finding a number of fossils in the Morte Slates and in different localities, but whether these were in part true Silurian fossils as maintained by Dr. Hicks and the Rev. G. F. Whidborne, or wholly Lower Devonian, Dr. Hicks had clearly shown that the suc. cession across North Devon was not continuous and unbroken as had been supposed. The discovery of the

NO. I 570 , vOL. 6I] 